\title{
Epidemiology of Intratemporal Complications of Otitis Media
}

\author{
André Maranhão ${ }^{1}$ José Andrade ${ }^{1}$ Valéria Godofredo ${ }^{1} \quad$ Rafaela Matos $^{1}$ Norma Penido ${ }^{1}$ \\ ${ }^{1}$ Department of Otolaryngology, Universidade Federal de São Paulo - \\ UNIFESP, Rua Dos Otonis, Sao Paulo, Brazil \\ Address for correspondence Andre Maranhão, MSc, Department of \\ Otolaryngology, UNIFESP, Rua Dos Otonis, 700, Sao Paulo 04025-002, \\ Brazil (e-mail: andre_maranhao@hotmail.com).
} Int Arch Otorhinolaryngol 2014;18:178-183.

\begin{abstract}
Keywords

- otitis media

- suppurative otitis media

- temporal bone

Introduction Despite the advent of antibiotics and immunizations in the last century, complications of otitis media remain quite frequent, have high morbidity and mortality rates, and pose a challenge to the otorhinolaryngologist.

Objective To establish the annual incidence of intratemporal complications of otitis media and prospectively evaluate patients via an analysis of epidemiologic and clinical aspects.

Methods Prospective, observational study. Between February 2010 and January 2011, patients admitted to a tertiary care, university-based otology practice with diagnosis of otitis media and an associated intratemporal complication (ITC) were included in the study. The following data were evaluated: age, sex, type of ITC, treatment, imaging tests findings, type and degree of hearing loss, and clinical outcome. The overall incidence of all complications and of each complication individually was determined.

Results A total of 1,816 patients were diagnosed with otitis media. For 592 (33\%) individuals, the diagnosis was chronic otitis media; for 1,224 (67\%), the diagnosis was acute otitis media. ITCs of otitis media were diagnosed in 15 patients; thus, the annual incidence of intratemporal complications was $0.8 \%$. We identified 19 ITC diagnoses in 15 patients ( 3 patients had more than one diagnosis). Labyrinthine fistulae were diagnosed in $7(36.8 \%)$ individuals, mastoiditis in 5 (26.3\%), facial palsy in $4(21.1 \%)$, and labyrinthitis in 3 (15.8\%).

Conclusion The incidence of intratemporal complications in Brazil remains significant when compared with developed countries. Chronic otitis media with cholesteatoma is the most frequent etiology of intratemporal complications. Labyrinthine fistula is the most common intratemporal complication.
\end{abstract}

\section{Introduction}

The rise in antibiotics use that began in the 1940s and increased throughout the last century dramatically reduced the incidence of complications from acute otitis media (AOM) and chronic otitis media (COM). Antibiotics replaced the then-prevailing surgical treatment approach with predominantly clinical treatment. ${ }^{1,2}$

Nevertheless, complications remain quite frequent, have high morbidity and mortality rates, and pose a challenge to the otorhinolaryngologist. ${ }^{3-9}$ At a 1998 World Health Organization meeting devoted to health policies for chronic middle ear infections, COM was signaled as an important and permanent public health problem; however, there is a lack of populationbased data on this subject. Several countries still need to compile epidemiologic data to establish the impact of COM and the priorities for its prevention and treatment. ${ }^{10}$ The studies on intratemporal complications (ITCs) of otitis media are mostly retrospective; some authors recommend the performance of more rigorous prospective studies on this subject. ${ }^{11}$ received

October 30, 2013

accepted

November 22, 2013
DOI http://dx.doi.org/

$10.1055 / \mathrm{s}-0033-1364172$ ISSN $1809-9777$.
Copyright $(2014$ by Thieme Publicações License terms Ltda, Rio de Janeiro, Brazil

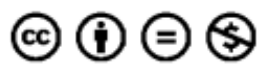


Table 1 Seasonal distribution of AOM according to age range

\begin{tabular}{|l|l|l|l|l|l|l|l|l|l|l|}
\hline \multirow{2}{*}{ Patient age (y) } & \multicolumn{2}{|c|}{ Summer } & \multicolumn{2}{|c|}{ Fall } & \multicolumn{2}{c|}{ Winter } & \multicolumn{2}{c|}{ Spring } & \multicolumn{3}{c|}{ Total } \\
\cline { 2 - 12 } & $n$ & $\%$ & $n$ & $\%$ & $n$ & $\%$ & $n$ & $\%$ & $n$ & $\%$ \\
\hline $0-10$ & 49 & 15.0 & 79 & 27.3 & 85 & 28.7 & 64 & 20.4 & 277 & 22.6 \\
\hline $11-20$ & 42 & 12.9 & 30 & 10.4 & 45 & 15.2 & 43 & 13.7 & 160 & 13.1 \\
\hline $21-30$ & 81 & 24.8 & 57 & 19.7 & 70 & 23.6 & 80 & 25.6 & 288 & 23.5 \\
\hline $31-40$ & 63 & 19.3 & 46 & 15.9 & 34 & 11.5 & 50 & 16.0 & 193 & 15.8 \\
\hline $41-50$ & 43 & 13.2 & 35 & 12.1 & 30 & 10.1 & 41 & 13.1 & 149 & 12.2 \\
\hline $51-60$ & 28 & 8.6 & 27 & 9.3 & 18 & 6.1 & 22 & 7.0 & 95 & 7.8 \\
\hline $61-70$ & 13 & 4.0 & 9 & 3.1 & 12 & 4.1 & 9 & 2.9 & 43 & 3.5 \\
\hline $71-80$ & 4 & 1.2 & 5 & 1.7 & 2 & 0.7 & 4 & 1.3 & 15 & 1.2 \\
\hline $81-90$ & 2 & 0.6 & 1 & 0.3 & & & & & 3 & 0.2 \\
\hline $91-100$ & 1 & 0.3 & & & & & & & 1 & 0.1 \\
\hline Total & 326 & 100.0 & 289 & 100.0 & 296 & 100.0 & 313 & 100.0 & 1,224 & 100.0 \\
\hline
\end{tabular}

Abbreviation: AOM, acute otitis media.

The objective of the present study is to establish the incidence of ITCs of otitis media over a 1-year period and prospectively evaluate the affected patients via an analysis of the disorder's epidemiologic and evolutional aspects.

\section{Methods}

From February 2010 to January 2011, patients admitted to a tertiary care, university-based otology practice who were diagnosed with (acute or chronic) otitis media and an ITC of otitis media were included in a prospective observational study of epidemiologic characteristics. The following variables were assessed: age, gender, type of ITC, treatment applied, imaging test findings, type and degree of hearing loss (during infection and after treatment), and clinical outcome. In addition, the overall incidence of complications and the incidences of each individual complication were determined. The data analyzed in patients with otitis without complications were age, gender, otologic diagnosis (AOM or $\mathrm{COM}$ ), and the seasonality of AOM and COM, divided according to age ranges (10-year intervals).

This project was approved by the research ethics committee under the number CEP 0081/10.

\section{Results}

During the 12 months of the study, 1,816 patients with an OM diagnosis were seen. Eight hundred seventy-three (48\%) were males and 943 (52\%) were females. Regarding diagnosis, 592 (33\%) patients had COM and 1,224 (67\%) had AOM. The seasonal distribution of AOM and COM according to age range is described in $\mathbf{- T a b l e s} \mathbf{1}$ and $\mathbf{2}$, respectively.

Table 2 Seasonal distribution of COM according to age-range

\begin{tabular}{|l|l|l|l|l|l|l|l|l|l|l|}
\hline \multirow{2}{*}{ Patient age (y) } & \multicolumn{2}{|c|}{ Summer } & \multicolumn{2}{c|}{ Fall } & \multicolumn{2}{c|}{ Winter } & \multicolumn{2}{c|}{ Spring } & \multicolumn{2}{c|}{ Total } \\
\cline { 2 - 11 } & $\boldsymbol{n}$ & $\%$ & $\boldsymbol{n}$ & $\%$ & $\boldsymbol{n}$ & $\%$ & $\boldsymbol{n}$ & $\%$ & $\boldsymbol{n}$ & $\%$ \\
\hline $0-10$ & 22 & 12.9 & 32 & 16.4 & 22 & 15.7 & 9 & 10.3 & 85 & 14.4 \\
\hline $11-20$ & 17 & 10.0 & 19 & 9.7 & 10 & 7.1 & 7 & 8.0 & 53 & 9.0 \\
\hline $21-30$ & 29 & 17.1 & 26 & 13.3 & 30 & 21.4 & 18 & 20.7 & 103 & 17.4 \\
\hline $31-40$ & 38 & 22.4 & 43 & 22.1 & 21 & 15.0 & 19 & 21.8 & 121 & 20.4 \\
\hline $41-50$ & 28 & 16.5 & 32 & 16.4 & 19 & 13.6 & 8 & 9.2 & 87 & 14.7 \\
\hline $51-60$ & 11 & 6.5 & 23 & 11.8 & 20 & 14.3 & 16 & 18.4 & 70 & 11.8 \\
\hline $61-70$ & 16 & 9.4 & 10 & 5.1 & 13 & 9.3 & 7 & 8.0 & 46 & 7.8 \\
\hline $71-80$ & 8 & 4.7 & 8 & 4.1 & 4 & 2.9 & 2 & 2.3 & 22 & 3.7 \\
\hline $81-90$ & 1 & 0.6 & 1 & 0.5 & 1 & 0.7 & 1 & 1.1 & 4 & 0.7 \\
\hline $91-100$ & & & 1 & 0.5 & & & & & 1 & 0.2 \\
\hline Total & 170 & 100.0 & 195 & 100.0 & 140 & 100.0 & 87 & 100.0 & 592 & 100.0 \\
\hline
\end{tabular}

Abbreviation: COM, chronic otitis media. 
Table 3 Intratemporal complications in 15 patients $^{\mathrm{a}}$

\begin{tabular}{|l|l|l|}
\hline Intratemporal complication & $\boldsymbol{n}$ & $\%$ \\
\hline Labyrinthine fistula & 7 & 36.8 \\
\hline Mastoiditis & 5 & 26.3 \\
\hline Peripheral facial palsy & 4 & 21.1 \\
\hline Labyrinthitis & 3 & 15.8 \\
\hline Total & 19 & 100.0 \\
\hline
\end{tabular}

${ }^{a}$ Nineteen diagnoses; two patients exhibited two types of complications and one patient exhibited three types of complications.

Of the 1,816 patients, 15 exhibited ITCs of otitis media, representing an annual incidence of $0.8 \%$. Of these 15 individuals, $9(60 \%)$ were females and $6(40 \%)$ were males. The otologic diagnosis was cholesteatomatous COM (CCOM) in 11 (74\%) patients, AOM in $3(20 \%)$ patients, and non-CCOM ( $\mathrm{NCCOM})$ in $1(6 \%)$ patient. The average age of the patients was 52 years old (range: 26 to 78 years).

Of the 15 individuals with ITCs, 2 patients exhibited 2 concomitant complications and 1 patient exhibited 3 complications, for a total of 19 ITC diagnoses. The frequency of each complication is described in - Table 3. One patient exhibited an associated intracranial complication (sigmoid sinus thrombosis). All these patients were admitted to the hospital and treated with intravenous antibiotics and corticosteroids. The distribution of the 19 complications is described in - Table 4.

Mastoidectomy was applied to $10(65 \%)$ patients. Seven (47\%) had undergone a previous mastoidectomy, and 4 (57\%) patients had had more than 1 previous mastoidectomy; in all of these cases, the otologic diagnosis was CCOM. The treatments are described in -Table $\mathbf{5}$. Comorbidities were present in $9(60 \%)$ patients, and systemic arterial hypertension (SAH) and diabetes mellitus (DM) were the most prevalent.

The frequency of the signs and symptoms preceding the complications, classified according to otologic diagnosis, is described in - Table 6 .

\section{Labyrinthine Fistula}

Seven patients were diagnosed with labyrinthine fistula; 4 (57\%) were males and 3 (43\%) were females. The annual incidence of this complication was $0.38 \%$. The average age
Table 5 Treatments applied to patients with complications (antibiotics and corticoids were given to all patients)

\begin{tabular}{|l|l|l|}
\hline Treatment & $\boldsymbol{n}$ & $\%$ \\
\hline Open mastoidectomy & 10 & 66.7 \\
\hline Simple (closed) mastoidectomy & 2 & 13.3 \\
\hline Retroauricular drainage & 1 & 6.7 \\
\hline Ventilation tube & 1 & 6.7 \\
\hline Nonsurgical & 1 & 6.7 \\
\hline Total & 15 & 100.0 \\
\hline
\end{tabular}

of the patients was 59 years old (range: 44 to 78 years). In 6 patients (86\%), the otologic diagnosis was CCOM; NCCOM was diagnosed in 1 patient (14\%). The disease had lasted more than 5 years in $6(86 \%)$ patients. - Table 7 summarizes the frequency of signs and symptoms.

Treatment was surgical in all cases; open mastoidectomy was performed in $5(84 \%)$ patients. Fistula repair consisted of placing a piece of temporalis fascia over the labyrinthine bone defect. One patient exhibited associated labyrinthitis.

On preoperative audiometry tests, all patients exhibited mixed hearing loss. In $43 \%(3 / 7)$, the hearing loss was moderate; in $43 \%(3 / 7)$, the loss was severe; and in $14 \%$ (1/7), the hearing loss was mild. Postoperative audiometry showed persistent mixed hearing loss; 2 patients $(27 \%)$ exhibited an average improvement of $20 \mathrm{~dB}$ in the tonal thresholds at $500,1,000$, and $2,000 \mathrm{~Hz}$, and $1(14 \%)$ patient exhibited a 15- $\mathrm{dB}$ worsening of the thresholds at those frequencies.

\section{Mastoiditis}

Mastoiditis was diagnosed in 5 patients ( 2 males and 3 females). The patients' average age was 44 years old (range: 26 to 66 years). The annual incidence of mastoiditis was $0.27 \%$. The otologic diagnosis was CCOM in $3(60 \%)$ patients and AOM in $2(40 \%)$. The disease had been diagnosed more than 5 years earlier in all patients with CCOM.

All 5 (100\%) patients exhibited earache and ear discharge, and $3(60 \%)$ presented with tinnitus. One patient $(20 \%)$ exhibited associated ITCs, evolving with peripheral facial palsy (PFP) and labyrinthitis, after beginning antibiotic treatment for mastoiditis; tympanocentesis was performed and a

Table 4 Distribution of the otologic diagnoses associated with complications $(n=19)$

\begin{tabular}{|c|c|c|c|c|c|c|c|c|c|c|}
\hline & \multicolumn{2}{|c|}{$\begin{array}{c}\text { Labyrinthine } \\
\text { fistula }(n=7)\end{array}$} & \multicolumn{2}{|c|}{$\begin{array}{l}\text { Mastoiditis } \\
\quad(n=5)\end{array}$} & \multicolumn{2}{|c|}{$\begin{array}{c}\text { Peripheral } \\
\text { facial palsy } \\
(n=4)\end{array}$} & \multicolumn{2}{|c|}{$\begin{array}{l}\text { Labyrinthitis } \\
\qquad(n=3)\end{array}$} & \multicolumn{2}{|c|}{ Total $(n=19)$} \\
\hline & $n$ & $\%$ & $n$ & $\%$ & $n$ & $\%$ & $n$ & $\%$ & $n$ & $\%$ \\
\hline AOM & & & 2 & 40.0 & 2 & 50.0 & 2 & 66.7 & 6 & 31.6 \\
\hline NCCOM & 1 & 14.3 & & & & & 1 & 33.3 & 2 & 10.5 \\
\hline CCOM & 6 & 85.7 & 3 & 60.0 & 2 & 50.0 & & & 11 & 57.9 \\
\hline Total & 7 & 100.0 & 5 & 100.0 & 4 & 100.0 & 3 & 100.0 & 19 & 100.0 \\
\hline
\end{tabular}

Abbreviations: AOM, acute otitis media; CCOM, cholesteatomatous chronic otitis media; NCCOM, non-cholesteatomatous chronic otitis media. 
Table 6 Frequency of signs and symptoms preceding complications according to otologic diagnosis

\begin{tabular}{|l|l|l|l|l|l|l|l|l|}
\hline \multirow{2}{*}{} & \multicolumn{2}{|c|}{ AOM $(\boldsymbol{n}=\mathbf{3})$} & \multicolumn{2}{c|}{ NCCOM $(\boldsymbol{n}=\mathbf{1})$} & \multicolumn{2}{c|}{ CCOM $(\boldsymbol{n}=11)$} & \multicolumn{2}{c|}{ Total $(\boldsymbol{n}=15)$} \\
\cline { 2 - 10 } & $\boldsymbol{n}$ & $\%$ & $\boldsymbol{n}$ & $\%$ & $\boldsymbol{n}$ & $\%$ & $\boldsymbol{n}$ & $\%$ \\
\hline Ear discharge & 3 & 100.0 & & & 11 & 100.0 & 14 & 93.3 \\
\hline Hearing loss & 3 & 100.0 & 1 & 25.0 & 9 & 81.8 & 13 & 86.7 \\
\hline Tinnitus & 2 & 66.7 & 1 & 25.0 & 8 & 72.7 & 11 & 73.3 \\
\hline Earache & 3 & 100.0 & 1 & 25.0 & 4 & 36.4 & 8 & 53.3 \\
\hline Vertigo & 1 & 33.3 & 1 & 25.0 & 5 & 45.5 & 7 & 46.7 \\
\hline Nausea/vomiting & 1 & 33.3 & & 0.0 & 2 & 18.2 & 3 & 20.0 \\
\hline Nystagmus & 1 & 33.3 & & 0.0 & 2 & 18.2 & 3 & 20.0 \\
\hline
\end{tabular}

Abbreviations: AOM, acute otitis media; CCOM, CCOM, cholesteatomatous chronic otitis media; NCCOM, non-cholesteatomatous chronic otitis media.

Table 7 Frequency of the signs and symptoms of patients with labyrinthine fistula

\begin{tabular}{|l|l|l|}
\hline Sign/symptom & $\boldsymbol{n}$ & $\%$ \\
\hline Hearing loss & 7 & 100.0 \\
\hline Tinnitus & 7 & 100.0 \\
\hline Ear discharge & 6 & 85.7 \\
\hline Vertigo & 5 & 71.4 \\
\hline Nystagmus & 2 & 28.6 \\
\hline Nausea/vomiting & 2 & 28.6 \\
\hline
\end{tabular}

ventilation tube was placed. This patient remained hospitalized and exhibited partial improvement of the symptoms until a simple mastoidectomy was indicated. This patient remained hospitalized for 32 days. After a thorough investigation, Wegener granulomatosis (WG) was diagnosed. After the initiation of cyclophosphamide and corticosteroid treatment, the PFP regressed completely, and the ear discharge improved.

The treatments provided included open mastoidectomy in 2 (40\%) patients, simple mastoidectomy in 1 (20\%) patient, retroauricular drainage in one (20\%) patient, and nonsurgical (isolated antibiotics) in 1 (20\%) patient.

Two (40\%) patients exhibited SAH as a comorbidity.

\section{Peripheral Facial Palsy}

Of the 4 patients diagnosed with PFP, 3 (75\%) were females 1 (25\%) was male. Their average age was 46 years old (range: 26 to 64 years). The annual incidence of PFP was $0.22 \%$. The otologic diagnosis was CCOM in $2(50 \%)$ patients and AOM in the other 2. In the patients with AOM, the disease had lasted 30 days before it was treated by the research staff of this study; in the patients with CCOM, the disease had lasted less than 10 days.

The PFP classification (according to House and Brackmann ${ }^{12}$ ) was grade IV in $3(75 \%)$ patients and grade III in 1 patient (25\%). Two (50\%) patients exhibited other associated complications; 1 was diagnosed mastoiditis and the other with labyrinthitis. Treatment was open mastoidectomy in 2 patients, simple mastoidectomy in 1 patient, and myringotomy with ventilation tube placement in 1 patient. The facial nerve was only surgically manipulated in cases where there was dehiscence of the fallopian canal; in these cases, the inflammatory tissue and/or cholesteatoma was carefully removed from the nerve sheath and adjacencies. The PFP evolved favorably in 3 patients and exhibited no changes in 1 patient.

\section{Labyrinthitis}

There were no cases of isolated labyrinthitis. Three patients exhibited labyrinthitis; the annual incidence of the disease was $0.1 \%$. All 3 patients had associated complications. Hearing loss, tinnitus, and vertigo were universally present, and nystagmus was observed in 2 patients.

All 3 patients were given corticosteroids for 4 weeks in decreasing doses. Two months after treatment, these patients reported complete improvement of tinnitus and vertigo and partial hearing improvement. The audiometric tests showed a 10- to 20-dB improvement at 500 to 1,000 and $2,000 \mathrm{~Hz}$ and persistent mixed hearing loss.

\section{Discussion}

The estimated annual incidence of ITCs of OM was $0.8 \%$, agreeing with studies performed in such developing countries as Thailand, ${ }^{8}$ Turkey, ${ }^{6}$ and Taiwan, ${ }^{3}$ which reported incidences of $0.45,1.35$, and $3 \%$, respectively. Although these values might not seem expressive, they become more relevant when compared with the incidence in industrialized countries such as Finland, for example, where a study found a $0.004 \%$ incidence of complications. ${ }^{11}$ The authors believe that difficulties with accessing the public health system, precarious assistance, and the population's lack of education contribute to the persistence of this situation, as other authors have also noted. ${ }^{4,13}$

COM predominated as the etiologic diagnosis of complications. CCOM in particular was associated with $74 \%$ of the complications. Although our sample was small $(n=15)$, a similar etiologic pattern also appeared in studies performed with larger numbers of patients. 6,8 
Approximately $60 \%$ of the complications were concentrated among patients 51 to 70 years old, and $80 \%$ of the patients in this group exhibited comorbidities, including SAH and DM. Although the duration of this study was short, the authors believe that these data should be considered because other authors have also reported a higher frequency of complications in elderly patients and patients with comorbidities. Lin et al, who retrospectively studied the occurrence of COM complications in a population of adolescents and adults for 10 years, observed that patients with complications were 49 years old on average and tended to exhibit comorbidities ( $38 \%$ had DM). ${ }^{3}$ We believe that comorbidities become more frequent with age, weakening the response to infections and consequently increasing the odds of developing complications. It is also worth noting that in the geriatric population, the signs of infections are subtle, ${ }^{14}$ which might somehow delay the identification of complications.

Regarding the signs and symptoms exhibited by patients with complications (-Table 6), it is worth distinguishing between patients with complications arising from AOM or from COM (both CCOM and NCCOM) because they exhibit marked differences. Earache was present in $100 \%$ of patients with AOM, whereas it was present in only $33 \%$ of patients diagnosed with COM. The signs and symptoms in patients with complications arising from COM are typically unspecific ones such as hearing loss and tinnitus, ${ }^{3}$ which were present in 84 and $75 \%$ of these patients, respectively. Moreover, these patients are usually older and exhibited associated comorbidities (as mentioned previously). Therefore, a high index of suspicion is needed for the early diagnosis and prevention of these complications.

\section{Labyrinthine Fistula}

In this study, labyrinthine fistula was the most frequent ITC; it represented $37 \%$ of complications and a $0.38 \%$ annual incidence. Its actual frequency is suspected to be even higher; studies of otitis media complications usually do not include all cases of labyrinthine fistula because often it does not cause significant symptoms and is only detected during surgery. ${ }^{13}$

Although the presence of neurosensory hearing loss, vertigo, and a positive fistula test in one patient with CCOM raised the suspicion of labyrinthine fistula, the absence of these findings does not confirm otic capsule integrity. For this reason, it is prudent to suspect a fistula in all cases with surgical indications.

In our case series, the lateral semicircular canal was affected in $100 \%$ of patients. Its proximity to the antrum makes it the most frequently affected part of the labyrinth; according to some authors, the lateral semicircular canal is involved in $\sim 90 \%$ of labyrinthine fistula cases. ${ }^{9,13}$

\section{Mastoiditis}

Mastoiditis was the second most common complication in our study, representing $20 \%$ of the complication diagnoses.

This study found a $0.27 \%$ annual incidence of mastoiditis. Despite its patent decline, mastoiditis remains a concern. In developing countries, mastoiditis and other complications remain the most common causes of death from COM. ${ }^{15}$

Although each type of OM-related complication may have a specific treatment, we believe that there are some therapeutic principles that might be extended to all complications. First, differentiating between AOM and COM is crucial. Virtually all AOM complications respond well to proper antibiotic treatment and myringotomy with or without ventilation tube placement. In cases of complications arising from COM, treatment must include broad-spectrum antibiotics that are effective against anaerobic and aerobic microorganisms, and some form of mastoidectomy is indicated in most cases. ${ }^{13}$ In our study, open mastoiditis was the treatment of choice for the three patients with mastoiditis whose otologic diagnosis was CCOM.

\section{Peripheral Facial Palsy}

Of the four patients with PFP, two had an otologic diagnosis of AOM and two had a diagnosis of COM. In this study, the annual incidence of PFP as a complication of OM was $0.22 \%$. Although this number may seem somewhat insignificant, it is similar to the incidences in the preantibiotic era, which were 0.5 to $0.7 \%{ }^{16,17}$ Conversely, the current incidence in developed countries is $\sim 0.005 \%$, as shown by a study performed in Denmark. $^{18}$

The two patients diagnosed with AOM in our study exhibited associated ITCs, namely labyrinthitis and mastoiditis. Hydén et al described seven cases of concomitant PFP and labyrinthitis in patients with AOM, and they postulated that an invasion of toxins or infectious agents, probably via the round window membrane, was followed by inflammatory damage to the nerve. ${ }^{19}$ Other authors described a strong association between AOM and PFP and labyrinthitis. ${ }^{11}$

The patient diagnosed with WG was hospitalized for 32 days until the diagnosis was made. Several authors noted the need to rule out WG, a rare condition that nonetheless may be present, especially in cases with a dissatisfactory evolution despite proper treatment. ${ }^{20-22}$

\section{Labyrinthitis}

There were three cases of serous labyrinthitis in our case series (all previously described) that were followed due to other ITCs, namely labyrinthine fistula, mastoiditis, and PFP. All patients reported hearing loss, tinnitus, and vertigo, and their audiometric tests showed moderate to severe mixed hearing loss. This was the most frequent complication in this study, with a $0.1 \%$ annual incidence.

The distinction between serous and suppurative labyrinthitis is only clinical and is based on the response to treatment and the audiometric improvement that patients with serous labyrinthitis exhibit.

\section{Conclusion}

The ITC of otitis media incidence in Brazil remains significant compared with that of developed countries. CCOM is the most frequent etiology of ITC of otitis media. Labyrinthine fistula is the most common ITC. 


\section{References}

1 Wanna GB, Dharamsi LM, Moss JR, Bennett ML, Thompson RC, Haynes DS. Contemporary management of intracranial complications of otitis media. Otol Neurotol 2010;31(1):111-117

2 Carvalhal LHSK, Costa SS, Cruz OLM. Complicações das otites médias. [Complications of the otitis media] In: Costa SS, Cruz OLM, Oliveira JAA, eds. Otorrinolaringologia: princípios e prática [Otolaryngology: principles and practice]. $2^{\circ}$ ed. Porto Alegre: Artmed; 2006, pp. 334-341

3 Lin YS, Lin LC, Lee FP, Lee KJ. The prevalence of chronic otitis media and its complication rates in teenagers and adult patients. Otolaryngol Head Neck Surg 2009;140(2):165-170

4 Dubey SP, Larawin V. Complications of chronic suppurative otitis media and their management. Laryngoscope 2007;117(2):264-267

5 Neves BMJ, Weckx LLM. Paralisia do nervo abducente como complicação de otite media aguda. [Abducens nerve palsy as a complication of acute otite media] Braz J Otorhinolaryngol 2002; 68:280-283

6 Osma U, Cureoglu S, Hosoglu S. The complications of chronic otitis media: report of 93 cases. J Laryngol Otol 2000;114(2):97-100

7 Penido NO, Borin A, Iha LCN, et al. Intracranial complications of otitis media: 15 years of experience in 33 patients. Otolaryngol Head Neck Surg 2005;132(1):37-42

8 Kangsanarak J, Fooanant S, Ruckphaopunt K, Navacharoen N, Teotrakul S. Extracranial and intracranial complications of suppurative otitis media. Report of 102 cases. J Laryngol Otol 1993; 107(11):999-1004

9 Smith JA, Danner CJ. Complications of chronic otitis media and cholesteatoma. Otolaryngol Clin North Am 2006;39(6):1237-1255

10 World Health Organization. Prevention of hearing impairment from chronic otitis media. Report of a WHO/CIBA Foundation Workshop. Geneva, Switzerland; Nov 19-21, 1996
11 Leskinen $\mathrm{K}$, Jero J. Acute complications of otitis media in adults. Clin Otolaryngol 2005;30(6):511-516

12 House JW, Brackmann DE. Facial nerve grading system. Otolaryngol Head Neck Surg 1985;93(2):146-147

13 El-Kashlan HK, Harker LA, Shelton C, Aygun N, Niparko JK. Complications of temporal bone infections. In: Cummings Otolaryngology Head and Neck Surgery. 5th ed. St. Louis: Mosby, Elsevier; 2010:1979-1998

14 Jarrett PG, Rockwood K, Carver D, Stolee P, Cosway S. Illness presentation in elderly patients. Arch Intern Med 1995;155(10): 1060-1064

15 Berman S. Otitis media in developing countries. Pediatrics 1995; 96(1 Pt 1):126-131

16 Bluestone $\mathrm{CD}$. Clinical course, complications and sequelae of acute otitis media. Pediatr Infect Dis J 2000;19(5, Suppl):S37-S46

17 Gaio E, Marioni G, de Filippis C, Tregnaghi A, Caltran S, Staffieri A. Facial nerve paralysis secondary to acute otitis media in infants and children. J Paediatr Child Health 2004;40(8):483-486

18 Ellefsen B, Bonding P. Facial palsy in acute otitis media. Clin Otolaryngol Allied Sci 1996;21(5):393-395

19 Hydén D, Åkerlind B, Peebo M. Inner ear and facial nerve complications of acute otitis media with focus on bacteriology and virology. Acta Otolaryngol 2006;126(5):460-466

20 Moussa AEM, Abou-Elhmd KA. Wegener's granulomatosis presenting as mastoiditis. Ann Otol Rhinol Laryngol 1998;107(7): 560-563

21 Takagi D, Nakamaru Y, Maguchi S, Furuta Y, Fukuda S. Otologic manifestations of Wegener's granulomatosis. Laryngoscope 2002; 112(9):1684-1690

22 Erickson VR, Hwang PH. Wegener's granulomatosis: current trends in diagnosis and management. Curr Opin Otolaryngol Head Neck Surg 2007;15(3):170-176 